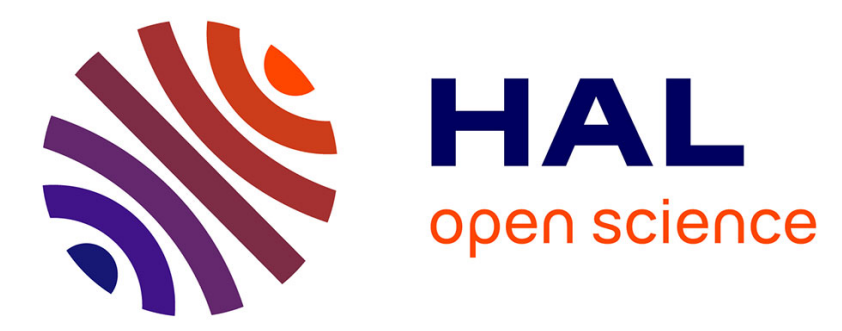

\title{
How to assess internal doses for epidemiological studies and for emergency response? An overview of differences with routine operational radiation protection approach
}

\author{
E. Davesne, O. Laurent, M.A. Lopez
}

\section{- To cite this version:}

E. Davesne, O. Laurent, M.A. Lopez. How to assess internal doses for epidemiological studies and for emergency response? An overview of differences with routine operational radiation protection approach. Radiation Measurements, 2018, 115, pp.20-28. 10.1016/j.radmeas.2018.04.014 . hal02874512

\section{HAL Id: hal-02874512 \\ https://hal.science/hal-02874512}

Submitted on 10 Jul 2020

HAL is a multi-disciplinary open access archive for the deposit and dissemination of scientific research documents, whether they are published or not. The documents may come from teaching and research institutions in France or abroad, or from public or private research centers.
L'archive ouverte pluridisciplinaire HAL, est destinée au dépôt et à la diffusion de documents scientifiques de niveau recherche, publiés ou non, émanant des établissements d'enseignement et de recherche français ou étrangers, des laboratoires publics ou privés. 


\title{
How to assess internal doses for epidemiological studies and for emergency response? An overview of differences with routine operational radiation protection approach
}

\author{
Estelle DAVESNE ${ }^{\mathrm{a}}$, Olivier LAURENT ${ }^{\mathrm{a}}$, María Antonia LOPEZ
}

anstitut de Radioprotection et de Sûreté Nucléaire (IRSN), PSE-SANTE/SDOS/LEDI, PSESANTE/SESANE/LEPID, Fontenay-aux-Roses, 92262, France.

${ }^{\mathrm{b}}$ Centro de Investigaciones Energéticas Medioambientales y Tecnológicas (CIEMAT), lonizing Dosimetry Unit, Avda. Complutense 40, 28040 Madrid, Spain

\section{ABSTRACT}

The main aim of internal dosimetry in the frame of operational radiation protection is the evaluation of committed doses to verify the compliance of internal exposures with regulatory dose limits. To better understand the biological effects of internal exposures (cancer and non-cancer diseases), epidemiological studies can be conducted for estimating radiation-induced risks associated with intakes of radionuclides. In case of high levels of exposure when radiological events occur and for risk assessment, appropriate calculations of absorbed doses in Grays (Gy) to organs and tissues of exposed persons are required, but no reference methodology is currently available for internal dose assessments using data collected for epidemiology studies. Epidemiological studies and radiological emergency response in case of exposure to internal emitters may require different approaches, tools and methods for dose assessment comparing with operational internal dosimetry. This publication presents an overview of specific procedures associated with internal dosimetry for emergency response and epidemiology studies.

\section{KEYWORDS}


Internal dosimetry, risk assessment, emergency response, epidemiology

\section{Introduction}

Internal contamination follows an intake of radionuclides into the body either by inhalation, ingestion, injection or wound. Whereas inhalation and wound are the most likely intake routes for workers occupationally exposed to radionuclides, ingestion of contaminated foodstuff can be an important source of exposure for public and injection is specific to medical exposures ${ }^{[1]}$. Following the intake, a given radionuclide is distributed inside the body according to its metabolism (for instance, iodine is preferably retained in the thyroid ${ }^{[2]}$ ) and delivers doses in the different tissues.

The energy absorbed in a tissue by unit of mass is defined as the absorbed dose $D$ in Grays ${ }^{[3]}$. Because of different effects induced in tissues by different radiation types and of varying tissue radiosensitivity, ICRP developed, for the purpose of operational radiation protection, the integrative concept of the quantity effective dose $E$ in Sieverts (Sv), defined as $E=\sum_{T} \sum_{R} w_{T} w_{R} D_{R, T}$, where $w_{T}$ is the weighting factor of tissue $T$ based on the tissue radiosensitivity (mostly derived from epidemiological studies in Japanese A-Bomb survivors), $w_{R}$ the weighting factor of radiation $R$ depending on the property of the radiation to generate damage in the tissue (mostly derived from Relative Biological Effectiveness (RBE) determined from experimental data) and $D_{R, T}$ the dose from radiation $R$ absorbed in tissue $T^{[3]}$. ICRP Publication $103^{[3]}$ provides reference values for $W_{R}$ and $W_{T}$ whereas the absorbed doses $D_{R, T}$ are estimated from the number of disintegrations occurring in a retention site determined from biokinetic models published by ICRP, the energy and probability to emit radiation $R$ at each disintegration, the mass of tissue $T$ and, in case of internal contamination, also from the fraction of energy absorbed in tissue $T$ from particles emitted following disintegrations in the retention site ${ }^{[4]}$. This absorbed fraction $(\mathrm{AF})$ is calculated by applying Monte-Carlo codes for radiation transport and using dosimetric models representing human anatomy. 
In the specific context of internal exposures, the irradiation of the human tissues by incorporated radionuclides lasts over time periods determined by their physical half-life and their biological retention inside the body because the energy deposition lasts as long as the radionuclide remains in the body. As a consequence, doses to body tissues may be protracted for many months or years after the intake. The accumulation of radiation dose over extended periods of time supports the definition of committed dose quantities: committed absorbed doses and committed effective doses.

Individual monitoring of internal exposures is carried out by 1) in vitro analyses allowing the identification and quantification (excretion rate e.g Bq. $\mathrm{d}^{-1}$ ) of alpha-, beta- and gamma-emitters in urine and faeces; 2) in vivo measurements allowing the determination of the retained activity $(\mathrm{Bq})$ of $\mathrm{x}$-ray and gamma-emitters in specific organs or in the whole body.

The interpretation of monitoring data in term of intake $(\mathrm{Bq})$ and of committed effective dose is carried out by comparing measurement values with retained/excreted fractions assuming an intake of $1 \mathrm{~Bq}$ and by multiplying the intake by the committed effective doses corresponding to an intake of $1 \mathrm{~Bq}$ (dose coefficients). Retained and excreted fractions after the intake of $1 \mathrm{~Bq}$ as well as dose coefficients are generated from biokinetic and dosimetric models and published by ICRP for dose evaluation purposes.

To adequately use biokinetic models when interpreting monitoring data for the dose assessment, the parameters related to the internal exposure must be well known or realistically assumed: the incorporated radionuclide(s), the intake pattern (chronic or acute), the time of intake (or period for chronic intakes), the chemical form and the particle size of the aerosol in case of inhalation. For example, an activity rate of $1 \mathrm{~Bq} . \mathrm{d}^{-1}$ of ${ }^{234} \mathrm{U}$ in urine may correspond to a committed effective dose of $3.5 \mu \mathrm{Sv}$ if the intake took place the day before, or to $960 \mu \mathrm{Sv}$ if the intake occurred 30 days before, or to $3.5 \mu \mathrm{Sv}$ for a soluble compound and of $9690 \mu \mathrm{Sv}$ for an insoluble compound. Therefore, when 
interpreting in vitro and in vivo measurement results to derive intakes and doses, the consistency of exposure conditions is of great importance. When exposure conditions are not precisely known, assumptions must be made in order to estimate doses. To help dosimetrists in taking decisions in a step-by-step dose evaluation different reference documents and guidelines have been published: ISO standard $27048^{[5]}$, EURADOS IDEAS guidelines ${ }^{[6]}$, European Technical recommendations for monitoring individuals for occupational intakes of radionuclides ${ }^{[7]}$, French society for occupational medicine ${ }^{[8]} \ldots$ Several computer programs are available to estimate doses from in vivo and in vitro measurements: AIDE ${ }^{[9]}$, IDEA System ${ }^{[10]}$, IMBA , ${ }^{[11]}$, IMIE ${ }^{[12]}$, MONDAL ${ }^{[13]}$, OPSCI $^{[14]} \ldots$ Although these tools and guidelines are of high practical value to estimate doses in routine operational radiation protection (RP) from a chronic or acute exposure, their use for risk assessment as part of epidemiological studies of occupational intakes or as part of emergency response is not always best suited because of the different requirements in these contexts, as discussed in the following sections.

\section{Dose assessment for emergency response}

\subsection{Context and challenges}

Radiation emergency exposures may occur during the operation of a planned situation, from a malevolent act or from any other unexpected event, requiring urgent action to prevent or reduce health effects of contaminated persons. Emergency workers are present on the nuclear site during the release of radioactive material, being directly involved in emergency actions to diminish the consequences of the accident. The number of emergency workers could be very large because they can be radiation workers from the nuclear facility, non-radiation workers or volunteers. Among them, first responders intervene at the scene of an emergency during the first few hours of a radiological emergency ${ }^{[15 ;}$ 16]. Emergency workers may include ambulance drivers, medical staff, 
policemen, fire fighters, civil protection and army personnel who may be exposed beyond occupational dose limits with the purpose of saving lives or to prevent disastrous consequences trying to mitigate the impact of the radioactive discharge on the health and life conditions of the exposed population and of the environment ${ }^{[7]}$.

According to EC Council Directive 2013/59/EURATOM ${ }^{[17]}$, emergency occupational exposure must remain if possible below the limit on the effective dose for occupational exposure (20 $\left.\mathrm{mSv} . \mathrm{y}^{-1}\right)$. For situations where this is not feasible, reference levels for emergency occupational exposure must be set below an Effective Dose of $100 \mathrm{mSv}$.

According to ICRP Publication $109^{[18]}$ when the emergency scenario may result in effective doses above $100 \mathrm{mSv}$, or when the resulting exposures are very strongly dominated by the irradiation of a single organ (e.g. radioiodine in thyroid), ICRP advices to provide reference levels in terms of organ doses.

The emergency intake scenario in an early phase generally consists of acute intakes through inhalation of volatile elements including iodine $\left({ }^{131} \mathrm{I},{ }^{132} \mathrm{I},{ }^{133} \mathrm{I},{ }^{134} \mathrm{I}\right.$, and $\left.{ }^{135} \mathrm{I}\right)$, caesium $\left({ }^{134} \mathrm{Cs},{ }^{136} \mathrm{Cs}\right.$, and $\left.{ }^{137} \mathrm{Cs}\right)$, tellurium $\left({ }^{132} \mathrm{Te}\right)$, and inert gases (e.g. xenon $\left.{ }^{133} \mathrm{Xe}\right)$. Information on weather conditions and magnitude of internal exposure should be reported. Regarding time of intake for dose evaluation, the exposure to radioactive plume and highest concentration of the activity in the air may be taken into consideration with a conservative approach for example by assuming an acute intake at the time of the beginning of the radioactive release ${ }^{[7]}$. The first concern of residents and evacuees in contaminated areas is internal exposure to radioiodine and associated thyroid cancer risk (especially for children). Major contribution of intake corresponds to ${ }^{131}$ I (half-life of 8.02 days). Once incorporated into the human body, radioiodine accumulates in the thyroid. Activity measurements of ${ }^{131} \mathrm{I}$ in the thyroid should be performed soon. Intakes of short-lived radionuclides such as ${ }^{132} \mathrm{Te} /{ }^{132}$ I or ${ }^{133} \mathrm{I}$ also occur at an early phase and can be missed if individual monitoring is not performed soon after the accident ${ }^{[19]}$. Radiocaesium intakes (incorporation mainly to ${ }^{134} \mathrm{Cs}$ and ${ }^{137} \mathrm{Cs}$ ) are easily detected in total body by gamma spectrometry (using whole-body 
counters) and doses can be well determined at any time of this early phase due to their longer half-life.

The emergency intake scenario in an intermediate phase may take account of continuous or incidental ingestion which contribute to the intake through food chain (this is difficult to evaluate). Rapid restriction on distribution and consumption of contaminated food and drink is required to minimize doses.

In this context, the challenges are 1) to establish an efficient individual monitoring program according to the intake scenario and the source term, with appropriate in vivo and/or in vitro bioassay techniques for a large number of individuals, for a rapid interpretation of monitoring data to estimate internal doses, 2) to quickly quantify the doses received by the exposed people: nuclear site workers, emergency workers (including first responders) and population (adults and children), 3) to identify people at highest risk (triage). 4) to transfer the dosimetry data to decision makers to support actions (medical treatment, evacuation and others) to reduce the risk of stochastic effects, based on the results of committed effective dose, and to avoid or minimize deterministic effects, based on absorbed dose estimates. In case of significant internal contamination, a decorporation treatment (administration of stable iodine, diethylene triamine pentaacetic acid (DTPA) or Prussian Blue) may be given as soon as possible, taking into account incorporated radionuclides and medical conditions of the exposed subject. A more reliable dose investigation for the identified individuals with highest exposure may be carried out in a second phase. Finally, an epidemiological study and follow up should be carried out during the post-accidental stage.

\subsection{Individual monitoring in emergency situations}

Workers and members of the public who could be potentially exposed to the incorporation of radioactive material during the radiological accident must be identified to be included 
in individual monitoring programs for the assessment of the intake and committed effective dose.

First responders exposed to a contaminated environment during a major accident at a nuclear site should be monitored for internal contamination following the same procedures as in a planned exposure situation ${ }^{[15]}$ on the basis of individual monitoring by authorized or approved dosimetry services that have implemented a quality management system ${ }^{[7]}$

Screening for potential external contamination must be performed prior to in vivo monitoring. Decontamination and rescreening will be carried out whenever external contamination is confirmed, to prevent intakes of radionuclides via ingestion and/or the skin and to avoid the transfer of the radioactive material to biological samples. Analysis of nose-blow samples or facial swipes permits to identify potential intakes via inhalation.

\section{In vivo monitoring of incorporated radionuclides: internal gamma emitters}

The main issue in case of onsite individual measurements of exposed population after an emergency event is the high level of environmental background. Field triage is possible for internal gamma emitters using mobile units of body counters, portable detectors (e.g. $\mathrm{Nal}(\mathrm{Tl}), \mathrm{HPGe}, \mathrm{LaBr} 3$ detectors performing gamma spectrometry) and other equipment (e.g. hand-held non-spectrometric devices such as dose rate monitors).

Whole-body counting facilities (WBC) outside the emergency area permit individual measurements are performed with lower level of background. This is recommended for the in-vivo monitoring of exposed people with highest internal exposure detected in the triage. Counting geometries of body counters must be adapted for children and appropriate calibration phantoms for adults and children are required and not always available. Agedependent efficiency calibration result in reliable retained activity calculations and estimation of reliable doses. 
As an alternative equipment to support individual monitoring of population at large scale, gamma cameras of hospitals may be used for screening purposes.

In all the cases mentioned above a proper efficiency calibration must be performed in advance prior to individual monitoring, taking into account the radionuclides to be detected, present in the radioactive plume.

\section{In vitro bioassay measurements}

In vitro measurements of the excretion rate in biological samples (mainly in urine and feces) of potentially internally exposed people are carried out when the radioactive release consists of alpha- or beta-emitters with photon emissions of very low energy or intensity, if the accident scenario involves uranium or actinide releases not measurable by in vivo monitoring, to confirm internal contamination in case of persistent external contamination and to improve the assessment of the internal dose when the exposure is significant ${ }^{[6 ; 7]}$.

Few mobile units for onsite analysis of biological samples are available around the world. On other hand, the main challenge for bioassay laboratories outside emergency area is how to handle samples of a big group of exposed people. Radiochemistry processes and sample turnaround in routine must be shortened, and this is not a trivial matter that needs further developments and research. Several intercomparisons on Emergency Bioassay has been organized recently by European Radiation Dosimetry Group (EURADOS), by REMPAN-WHO (Radiation Emergency, Medical Preparedness and Assistance Network, also by GHSI (Global Health Security Initiative Lab. Network) and PROCORAD Association on radiotoxicology ${ }^{[20-}$ ${ }^{22]}$. The objective of all these actions is for laboratories to develop and to validate methods with sensitivity enough to meet the requirements for emergency bioassay in typical nuclear accident scenarios. 


\subsection{Dose Assessment and Dose Reconstruction}

Individual dose assessment for workers and population are based on environmental and individual monitoring data and should take into account histories of locations, food habits, indoor/outdoor stay... of the exposed individuals. The committed doses due to internal exposures have to be evaluated during emergency phase (the passage of the plume), the transition phase to a post-accidental situation (counter measures not implemented yet) and the long-term post-accidental phase (residual contamination in the locations affected by the accident).

Initial assessment of the committed effective dose is performed to know how significant is the intake and the need for medical assessment. Decisions will be taken on the need for additional monitoring and more accurate dose assessments after a positive result. The ISO standard $27048^{[5]}$ approach for internal dose assessment may be used for this purpose.

If individual monitoring is not possible at an early stage of the emergency situation, the isotopic composition of the contaminants should be known (e.g. from environmental measurements) for dose reconstruction. This is especially important in case of intakes of short-lived radionuclides. Higher uncertainty is involved on this kind of dose assessments compared with dose estimates using individual monitoring data. Exposure conditions, locations and working times should be taken into consideration for dose reconstruction. Concerning the characteristics of the contaminant, when no other information is available, an Activity Median Aerodynamic Diameter (AMAD) of $5 \mu \mathrm{m}$ should be considered for the emergency workers contaminated on the site and an AMAD of $1 \mu \mathrm{m}$ should be considered for those contaminated outside the nuclear facility ${ }^{[7]}$.

Dose reconstruction of thyroid doses of exposed population was an important challenge after the Fukushima Daiichi NPP accident ${ }^{[23]}$.

Regarding dose recording and reporting, a database associated to the radiation accident is recommended for recording all the individual monitoring results and final dose evaluations, together with the information about medical treatments and interventions. Reporting to 
individuals may require advice from experts for interpreting monitoring data, dose assessments and to communicate associated health risks, especially for population and workers who are not routinely exposed to radiation. Main concern of monitored people is the potential health effects associated to the evaluated internal exposure. Communication with exposed individuals and authorities has to be well established as an important part of the emergency management plan. A medical and/or dosimetry follow-up could be considered and programmed according with dosimetry results.

A quality management system should be implemented in the whole internal dosimetry process to guarantee reliability in monitoring data and in dose assessments.

In case of high level of internal exposures, ICRP Publication $103^{[3]}$ indicates that effective dose is not an appropriate quantity for the evaluation of deterministic effects. In this case, ICRP establishes that doses should be evaluated in terms of absorbed doses (in Gray, Gy) in an organ/tissue, and if high-LET radiation is involved (e.g. alpha particles) and absorbed dose weighted with an appropriate RBE should be used ${ }^{[3]}$. The SI unit used to express the

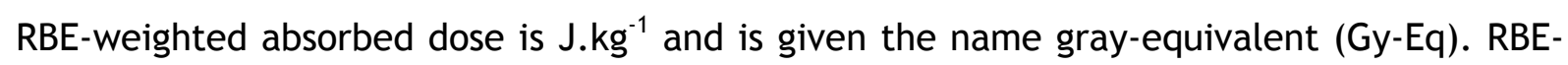
weighted absorbed dose, calculated using a 30-day integration period for absorbed dose may be compared to the generic reference levels for medical actions given in IAEA EPRMedical ${ }^{[7 ; 24]}$.

RBE values are given in an IAEA EPR-Medical publication ${ }^{[24]}$ which assumes, for example, a RBE of 0.2 for ${ }^{131}$ I irradiating internally the thyroid gland and a RBE of 2 for alpha particles irradiating internally the red bone marrow ${ }^{[7]}$. Organs for which absorbed doses can be calculated include lungs, red bone marrow colon and thyroid for radioactive isotopes of tellurium, iodine, technetium, and rhenium ${ }^{[24]}$. 


\subsection{Recent developments and needs}

The lessons learned from the Fukushima Daiichi NPP accident permitted to identify important gaps in monitoring and dose assessments when intakes of radionuclides occur in an emergency scenario. Procedures and tools need to be improved to guarantee reliable internal dosimetry and rapid response. European Commission, ICRP, REMPAN/WHO, IAEA, NERIS, EURADOS, RENEB and other organizations promoted workshops and research actions that have contributed to improve the management, decision making and networking for future emergency situations. Some relevant information about recent, current and future developments in this field is presented as follows.

TMT Handbook ${ }^{[25]}$ for the management of the public in the event of a malevolent use of ionising radiation provides information and recommendations for triage, monitoring, medical treatment and follow-up of people exposed to ionising radiation following a malevolent act. This guide considers emergency response not focused on nuclear power plant accidents but in situations such as a terrorist attack or a dirty bomb where the number of affected people can vary from few persons to mass casualties.

CATHYMARA Project ${ }^{[26] ~ " C h i l d ~ a n d ~ A d u l t ~ T h y r o i d ~ M o n i t o r i n g ~ A f t e r ~ R e a c t o r ~ A c c i d e n t " ~}$ project looked for optimal monitoring strategies for the assessment of absorbed doses resulting from intakes of all relevant radionuclides, but focusing on the monitoring and evaluation of thyroid doses resulting from intakes of ${ }^{131} \mathrm{I}$. Main outcomes of this research action are:

- A survey presenting on emergency plans and means at national level, focusing on thyroid measurements for adults and children. A study was elaborated comparing existing European emergency plans with the expectations of the civil society.

- Two intercomparison exercises of in vivo measurements for radioiodine in the thyroid were carried out: 1) Measurements were performed with mobile units and portable gamma spectrometry detectors and 2) with non-spectroscopic devices. Age specific thyroid 
phantoms of unknown activity were distributed to European participants. Proper Efficiency calibration of the equipment was required prior to the reception of the radioactive source. Results were satisfactory in both cases, showing the appropriateness of using for example dose-rate meters or gamma cameras from hospitals for individual monitoring for screening purposes.

- A Monte Carlo study of parameters influencing in vivo thyroid counting was carried out using realistic anthropomorphic voxel phantoms corresponding to $1,5,10,15$ years and adult, and four previously validated detector models ( $3 \mathrm{Nal}(\mathrm{Tl})$ detectors and 1 Germanium detector).

- Regarding the assessment of doses from monitoring data, dose per unit of activity content coefficients were developed for radioiodine isotopes, for various ages and for the foetus. The cases of non-measured short-lived radionuclides and iodine prophylaxis were also considered. A software to use for emergency monitoring and thyroid dose calculation was developed and is freely accessed at least until May 30th, 2019. The software is available from the web to be used (1) as a professional tool for direct dose calculation from measured thyroid activity for the radioiodine isotopes released during a reactor accident, for different age groups and (2) as a self-measurements reporting tool to report measurement performed by non-professional population and it is currently available for using dose-rate meters. These tools ${ }^{[27]}$ could be used as starting point for future developments on official basis and can be downloaded at:

- Professional simple dose evaluator https://cathymara.fjfi.cvut.cz/cdata

- Professional complex dose calculator https://cathymara.fjfi.cvut.cz/cdata/profi

- Self-measurement calculator https://cathymara.fjfi.cvut.cz/cdata/self

SHAMISEN Project ${ }^{[28]}$ dealt with nuclear emergency situations for the Improvement of Medical Surveillance starting with the lessons learned from experiences of exposed population due to the radiation accidents of Fukushima Daiichi and Chernobyl NPPs. The 
objective was to develop recommendations for early, intermediate and long-term emergency response, focusing on health surveillance (medical checks and treatments, surveys through questionnaires, follow-up) and communication with people (workers and population) affected by radiation accidents. SHAMISEN project aims to minimize social and psychological consequences, improving health and living conditions of exposed persons taking into account ethical issues involved in the whole decision making process. Shamisen recommendations also cover post-accidental epidemiology studies and dose reconstruction to evaluate if the radiation accident has impacted disease risk and to improve the knowledge on effects of radiation using analytical epidemiology approaches.

\section{$\begin{array}{llll}\text { CONFIDENCE } & \text { Project } & \text { (H2020 2017-2020, }\end{array}$}

https: / / portal.iket.kit.edu/CONFIDENCE/index.php?action=confidence\&title=objectives)

"COping with uNcertainties For Improved modelling and DEcision making in Nuclear emergenCiEs". This research action starts with the identification of gaps on emergency management, concentrating on early and transition phases. An international consortium was created counting with the expertise from the European Platforms on Radiation Protection with the objective of modelling and reducing uncertainties to improve radioecological predictions and emergency management (NERIS and ALLIANCE), situation awareness and monitoring strategies (EURADOS), risk estimation in the early phase (MELODI), decision making and strategy development at local and national levels (NERIS) including social and ethical aspects. Regarding dosimetry aspects, apart from the uncertainty study the aim here is the development of procedures and tools integrating monitoring data and dose assessments due to external and internal exposures to obtain a rapid and comprehensive picture of the radiological situation, linking them with risk assessment tools to support decision making (e.g. for medical treatments). Software tools for cancer risk assessment of contaminated people will be developed and used as an input in the overall decision making process. 
As a summary, research actions to improve emergency response to intakes may be focused on the improvement of the calibration of in vivo techniques for children monitoring, the use of Monte-Carlo methods and computational phantoms (Voxel phantoms, Mesh phantoms) for the calibration of body counters and the assessment of internal doses in case of radiation accidents, the studies on more rapid in vitro emergency bioassay methods especially for alpha emitters (actinides), the modelling of biokinetics of chelating agents for the interpretation of monitoring data in case of decorporation therapy (e.g. DTPA therapy model), development of appropriate and validated software for the calculation of committed effective doses to the public (using age dependent dose coefficients) and for the assessment of absorbed doses, application of biodosimetry methods to accidental internal exposures, to improve dose reconstruction for short-lived radionuclides, the rapid transfer of dosimetric data to decision-makers and a more effective communication of internal dosimetry experts with stakeholders and exposed persons.

All these recent achievements and developments still to be made aim at the determination of dose to estimate health risks from radionuclides incorporated following emergency exposures in the early or post-accidental phases. Other populations are currently studied to assess the risk potentially generated by radioactive intakes. For these populations, to determine doses is also not straightforward and will be presented in the next section of this article. 


\section{Dose assessment for epidemiological studies of}

\section{occupational intakes}

\subsection{Evaluation of risk associated with occupational intakes of radionuclide in epidemiological studies}

As explained above, the estimates of risk associated with intakes of radionuclides, except for radon and lung cancer ${ }^{[29]}$, are up to now based on the epidemiological follow-up of Hiroshima and Nagasaki A-Bomb survivors and on the ICRP approach including biokinetic and dosimetric models along with weighting factors. Although this approach is of practical value for radiation protection, it is important to verify if (and if so to which extent) the underlying hypotheses (transpositions of risks between populations, extrapolation to low doses and low dose rates, effects of different radiation types reflected by the $w_{T}$ ) adopted by the ICRP, mainly for the prevention of cancer incidence, are valid in case of internal exposures involving intakes of various radionuclides. In addition, whether internal contamination can induce non-cancer effects also needs to be investigated further. This is why epidemiological studies are conducted in different populations of subjects exposed to incorporated radionuclides, including workers which is one of the best suited groups to conduct studies on the effects of internal emitters thanks to their regular surveillance by the occupational medicine ${ }^{[30]}$ and dosimetry services. Of particular interest in these studies is the assessment of the risk of disease associated with absorbed doses (in Gray) to different organs.

Numerous studies have been conducted to investigate the health effects of occupationally incorporated radionuclides in radium watch dial painters ${ }^{[31 ; 32]}$, workers exposed to polonium ${ }^{[33]}$, uranium miners ${ }^{[34-36]}$ and millers ${ }^{[37-39]}$, Mayak plutonium workers ${ }^{[40-42]}$, uranium enrichment workers ${ }^{[43 ; 44]}$ and European nuclear workers exposed to alpha emitters ${ }^{[45 ; 46]}$. Among this non-exhaustive list of studies, individual internal doses 
following occupational intakes were assessed from in vivo or in vitro measurements only for Mayak ${ }^{[47]}$, uranium enrichment ${ }^{[48]}$, polonium ${ }^{[33]}$, and other nuclear workers ${ }^{[46 ; 49]}$.

Despite the publication of several guidelines on committed dose estimation for operational radiation protection, no reference method is available to estimate internal doses from data gathered in epidemiological studies although substantial differences exist in what concerns purposes (type of radionuclide and population, i.e.: general population or workers), requirements and available data.

\subsection{Data available for dose assessments}

For uranium miners, exposure to radon and its decay products has been reconstructed with job-exposure matrices, ambient or personal monitoring $\left(\right.$ e.g. ${ }^{[34-36]}$ ) but no bioassay data were available.

For some Mayak workers, ambient air monitoring and/or in vivo and in vitro measurements and/or autopsy data are used by dosimetrists to reconstruct exposure ${ }^{[50]}$. For American enrichment workers, urine measurements and information on chemical forms are available [51]. Urinary polonium analyses were also used to reconstruct exposure to polonium in Mound workers ${ }^{[33]}$.

Bioassay data for the monitoring of uranium exposure have been collected in several cohorts of the United Kingdom and Belgium, as summarized in Laurent et al. ${ }^{[52]}$. Bioassay analysis of plutonium and uranium in UK were used along with exposure information such as chemical forms to estimate doses ${ }^{[49 ; 53-58]}$. A cohort of uranium workers of the nuclear cycle in France, TRACY, has been set up and is still under development ${ }^{[59]}$. Information on exposure has already been collected for about one third this cohort: in vivo and in vitro measurement results (when carried out) from a growing number of workers of the cohort, incident registers providing information on abnormal events and job-exposure matrices 
providing information on chronic exposure periods at workplaces, including the different handled uranium compounds ${ }^{[44 ; 60 ; 61]}$.

These data are highly valuable to estimate internal doses but their interpretation presents additional challenge for estimating retrospective doses for epidemiology, by comparison with similar data provided for operational radiological protection (RP) purposes.

\subsection{Differences between dose evaluation for radiation protection (RP) and for epidemiological risk assessments}

In this section, the differences between dose evaluation for operational RP and for risk assessments in occupational settings are reviewed in details and are summarized in Table 1.

Regarding operational RP in occupational settings, internal committed doses are evaluated to verify the compliance (or to identify non-compliance) of exposure with regulatory dose limits. In most situations, overestimation is not an issue contrarily to underestimation which can be problematic. When estimating radiation-induced risks as part of epidemiological studies, if for instance a linear increase in risk associated with the "true dose" is assumed, dose overestimation would lead to an underestimation of the excess relative risk per unit of dose whereas an underestimation of the dose would result in to an overestimation of the excess relative risk per unit of dose. Therefore, for epidemiological risk assessment, unbiased dose estimates are needed while overestimation is sometimes accepted in operational RP.

Effective dose is the quantity specially developed for radiation protection because it allows the addition of the contributions from internal and external exposures and is of practical value for risk management. The ICRP approach for effective dose when is used for intakes of radionuclides, is to refer to a commitment period of 50 years for workers and 
to reference dosimetric and biokinetic models. As a result, published dose coefficients together with the calculated intake are used for the assessment of committed effective dose in Sv, with no uncertainty associated. The epidemiology approach, instead of committed effective doses, considers absorbed doses over specific periods of a lifetime (usually, over each year of life following the first exposure) in relevant tissues such as lungs, liver or others. However, annual absorbed doses are usually not routinely tabulated and validation can be tricky.

The number of dose assessments differs greatly between operational RP and risk assessment. For the first one, doses may be assessed only for workers with abnormal monitoring data (e.g. above recording or reporting level established by national regulations). The total number of calculations depends on the facilities: in France, in nuclear industry facilities only two internal doses were registered in $2015^{[62]}$. Intakes are estimated depending the frequency of the individual monitoring program or following an abnormal event from a limited number of in vivo and/or in vitro measurements. On the other hand, for epidemiological studies doses must be determined for the entire study population (e.g. a cohort). The total amount of dose estimates depends on the cohort but for the 3,000 workers of TRACY cohort with available bioassay data ${ }^{[59]}$, intakes must be derived for each worker's whole career from a database of more than 100,000 in vivo and in vitro measurements. Such large amounts of data and of dose calculations require automation, whereas this is not the usual scenario for operational internal dose assessments in case of routine or special monitoring of exposed workers. Different programs were developed to derive annual absorbed doses for epidemiological studies: the Mayak Worker Dosimetry System-2013 for the Mayak cohort ${ }^{[47]}$, PuMA and IMBA for Sellafield workers ${ }^{[58]}$, InDep ${ }^{[48]}$ for uranium enriched workers and DOSEPI for the TRACY cohort ${ }^{[46]}$.

Urine, faeces, lung, whole-body measurement data are available for both operational RP and epidemiology in case of occupational exposure situations. The main difference is that 
in RP, if needed, further in vivo or in vitro analyses may be performed, more sensitive techniques may be used and re-analysis may be possible in order to provide new data, whereas for epidemiological studies, only the best estimate of dose from available data has to be derived because no new data can be provided for past exposures (years to decades ago). For measurements below limit of detection, in operational RP, the value of the limit is known and there is a possibility of contacting the laboratory to try to improve the result, or to obtain uncensored result with uncertainty leading to refined dose estimates. For some data below limit of detection (DL) or reporting level (RL) in epidemiological databases, the actual value of the limit is not given because the results are literally registered as " $<\mathrm{DL} / \mathrm{RL}$ ". These levels have therefore to be reconstructed from historical records of laboratory practices and from similar bioassay results with recorded DL/RL available for the same site and time period. Moreover, sometimes no specific information is available on collection period for in vitro measurement, on measurement techniques, on date of sampling, and on measurement uncertainty. In operational RP, all this information is usually provided leading to a higher reliability of the data.

When reconstructing doses from in vitro and/or in vivo measurement gathered for epidemiological studies, it is not always known if the measurement was part of a routine or special monitoring and there is often scarce information of exposure period from incident registry, medical files, ambient air monitoring or interviews. For routine exposure however, valuable information can be provided by job-exposure matrices ${ }^{[60 ;}{ }^{61]}$. In operational RP, the purpose of the measurement is known along with knowledge on exposure periods from normal working conditions, high risk activity dates or air sampler alerts for acute intakes. Moreover, it is possible to ask workers or managers for more detailed information if needed.

Physico-chemical parameters can be derived from identified individual workplace and operations and sometimes precise chemical forms, particle size distribution and/or isotopic composition are known in operational RP. If needed, more precise data can be 
obtained by contacting the worker and radiation protection services. In epidemiological studies, if a job-exposure matrix is available, it can provide data on usual chemical forms and isotopic composition encountered at a specific job and period. Particle sizes are rarely known.

In operational RP, uncertainties associated to monitoring data are taken into account for the calculation of the intake and for checking the goodness of fit of measurement results with the prediction of the retention/excretion model for the intake scenario which occurred or is assumed. However, according to ICRP, dose coefficients have no uncertainty associated. Therefore committed effective doses are assessed without uncertainty associated. On the other hand, in epidemiological studies, confidence interval on dose assessments should be provided and uncertainty integrated in risk assessment.

In a nutshell, in operational RP, dose estimates can be refined by new data from new measurements or from inquiries. Dose estimated in the context of epidemiological study must make the best use of available data because no new data can be added. The following question is how to achieve this goal. 
Table 1: Summary of the differences in dose assessments carried out for operational radiation protection or for risk assessment

\begin{tabular}{|c|c|c|}
\hline & Doses for operational radiation protection & Doses for epidemiological risk assessment \\
\hline Purpose & $\begin{array}{l}\text { To verify the compliance or not of exposure with dose limits. } \\
\text { Overestimation is sometimes preferred (Conservative approach). }\end{array}$ & $\begin{array}{l}\text { To assess the risk of health effects associated to internal } \\
\text { exposures. Need for unbiased estimates. }\end{array}$ \\
\hline Output & Committed effective dose $\mathrm{E}(50) \mathrm{Sv}$ & $\begin{array}{l}\text { Absorbed doses (Gy), typically over each year of life following } \\
\text { exposure, in relevant tissues }\end{array}$ \\
\hline $\begin{array}{l}\text { Number of dose } \\
\text { assessments }\end{array}$ & $\begin{array}{l}\text { Doses assessed for workers with abnormal monitoring results } \\
\text { (e.g. above recording or reporting level) from a limited number } \\
\text { of in vivo and/or in vitro measurements. Hand calculation is } \\
\text { possible. }\end{array}$ & $\begin{array}{l}\text { Doses assessed for the whole cohort. Automation calculation is } \\
\text { necessary. }\end{array}$ \\
\hline $\begin{array}{l}\text { Type of } \\
\text { measurements }\end{array}$ & $\begin{array}{l}\text { Urine, feces, lung, whole-body monitoring data. Possibility of } \\
\text { additional data. }\end{array}$ & $\begin{array}{l}\text { Urine, feces, lung, whole-body monitoring data, sometimes } \\
\text { environmental (e.g. ambient air) samples. Impossibility of } \\
\text { additional data }\end{array}$ \\
\hline $\begin{array}{l}\text { Measurements below } \\
\text { detection limit }\end{array}$ & $\begin{array}{l}\text { Known detection limit and possibility of contacting the } \\
\text { laboratory to try to improve the result or to obtain uncensored } \\
\text { result with uncertainty }\end{array}$ & $\begin{array}{l}\text { Actual value of the detection limit sometimes is not specified in } \\
\text { the individual records. If so it has to be reconstructed from } \\
\text { laboratory historical records }\end{array}$ \\
\hline $\begin{array}{l}\text { Measurement } \\
\text { reliability }\end{array}$ & Good reliability of the monitoring data & $\begin{array}{l}\text { Lower reliability in some historical monitoring data due to } \\
\text { scarce knowledge on collection period for in vitro } \\
\text { measurement, on measurement techniques, on date of }\end{array}$ \\
\hline
\end{tabular}


sampling, and on measurement uncertainty.

Information from normal conditions, or high risk activity dates

Exposure period and air sampler alerts for acute intakes. Possibility of asking worker or manager for more precise information.
Scarce information of exposure period from incident registry, medical files, ambient air monitoring or interviews. Valuable information for routine exposure provided by job-exposure matrix if available.

\begin{tabular}{llc}
\hline Physico-chemical & Precise data available by contacting the worker and radiation & Information on chemical forms and isotopic composition if \\
parameters & protection services & incident registry and/or job-exposure matrix available
\end{tabular}

Uncertainties associated to monitoring data are taken into

account for the calculation of the intake and for checking the goodness of fit of measurement results with the prediction of

Uncertainties the retention/excretion model for the intake scenario occurred or assumed. According to ICRP, dose coefficients have no uncertainty integrated in risk assessment.

uncertainty associated therefore committed effective doses are

assessed without uncertainty associated. 


\subsection{Discussion}

Guidelines developed to assess doses due to internal exposures in the context of operational radiation protection such as the ISO standard $27048^{[5]}$ or the EURADOS IDEAS Guidelines ${ }^{[6]}$ recommend acquiring additional monitoring data to limit uncertainty in dose assessment. As discussed previously, this is impossible when estimating doses from historical data collected retrospectively for epidemiological studies of occupational intakes.

Various protocols were developed to estimate doses for epidemiological studies: ${ }^{46 ;} ; 4 ; 49 ; 51$; 54; 58]. During the Concerted Uranium Research in Europe (CURE) project funded by European Commission ${ }^{[52]}$, a dosimetric protocol was developed for future epidemiological studies of occupational uranium intakes ${ }^{[63]}$. Differences exist among these protocols because some are based on data not collectable for other studies like autopsy data in the Mayak cohort or because dosimetrists made different hypotheses for a same parameter. That is why when comparing the different documents, a set of reasonable hypothesis can be extracted for several parameters. One of the critical hypotheses is the estimation of internal doses from in vitro and/or in vivo measurements below detection limit. In the CURE protocol, when all data are below detection limit, it is recommended to estimate an interval of doses by fixing all the in vitro and/or in vivo results equal to zero or by modifying just the value the last bioassay from below the limit of detection in equal to the limit of detection ${ }^{[63]}$. Anderson et al. ${ }^{[51]}$ replaced monitoring data below detection limit by a value equal to the multiplication of the detection limit by to the fraction of bioassay higher than the detection limit in the individual's bioassay data set except for workers with only below detection results for which a dose equals to zero was assigned. In the SOLO project ${ }^{[54 ; 58]}$, Bayesian approaches were used to derive dose probability distributions and the value used for the epidemiological analyses was the arithmetic mean of this distribution. No differences were made between workers with or without measurement 
higher than detection limit in their data set. For European nuclear workers ${ }^{[49]}$, depending on the site, workers with only data below detection limits were either excluded from the study, or the last measurement result in the exposure period was set equal to the limit of detection or the dose was estimated as the median of the dose probability distribution provided by a Bayesian approach. All these modelings are methods to take the best advantage of the available data even if they are below detection limit. However, in order to compare exposure and risks between cohorts, a harmonized protocol would be essential. The development of such a protocol would be a real challenge for internal dosimetrists around the world and would lead to deep discussion on which modelling would be the best. A first step towards this harmonized protocol would be to apply the different protocols to the same group of workers in order to quantify the influence of the protocol on dose estimates. Then, each modelling of each parameter could be tested to quantify the sensitivity of doses to each modelling strategy.

Finally, as uncertainty analysis on internal dose assessments is an important issue ${ }^{[56]}$, to provide confidence interval on dose would be an advantage for the determination of the risk, at least to help identifying groups of subjects - or even studies - with the most precise dose estimates and thereby to conduct specific analyses in these subjects or weight causal judgements arising from several studies. Again, a standardized approach should be developed to provide doses with uncertainty in epidemiological studies. Last, integrated approaches to account for the uncertainty inherent in estimates of dose when evaluating radiation-induced disease risk must be developed. Testing and comparing such approaches will be necessary steps to achieve this goal ${ }^{[52]}$.

\section{Conclusions}

This publication presents an overview of specific procedures associated with internal dosimetry for emergency response and epidemiology studies. 
As a summary, research actions were identified that needed to be developed for improving emergency response when dealing with internal exposures. Such actions may be focused on the improvement of the calibration of in vivo techniques for children monitoring (including the development and validation of reference calibration phantoms scaled by age), the use of Monte-Carlo methods and computational phantoms (Voxel phantoms, Mesh phantoms) for the calibration of body counters and the assessment of internal doses in case of radiation accidents, the studies on more rapid in vitro emergency bioassay methods especially for alpha emitters (actinides), the modelling of biokinetics of chelating agents for the interpretation of monitoring data in case of decorporation therapy (e.g. DTPA therapy model), development of appropriate and validated software for the calculation of committed effective doses to the public (using age dependent dose coefficients) and for the assessment of absorbed doses, application of biodosimetry methods to accidental internal exposures, to improve dose reconstruction for short-lived radionuclides, the rapid transfer of dosimetric data to decision-makers and a more effective communication of internal dosimetry experts with stakeholders and exposed persons.

Regarding epidemiology studies and the assessment of the risk of health effects associated with accidental internal exposures, the main goal for the future is developing protocols and tools for improving the reliability of dose assessment in order to compare exposures and risks between cohorts. This could start with the quantification of the sensitivity of doses to each modelling strategy. Then, a standardized approach should be developed to provide uncertainty and confidence interval on dose. Last, integrated approaches to account for the uncertainty inherent in estimates of dose when evaluating radiationinduced disease risk must be developed.

\section{REFERENCES}


1. UNSCEAR, 2008. Sources and Effects of Ionizing Radiation, Report of the general Assembly with Scientifc Annexes, Volume I: Sources. United Nations, New-York.

2. ICRP, 1989. Age-dependent doses to members of the public from intake of radionuclides: Part 1. ICRP Publication 56. Annals of the ICRP 20.

3. ICRP, 2007. The 2007 Recommendations of the International Commission on Radiological Protection. ICRP Publication 103. Annals of the ICRP 37.

4. Bolch, W. E., Eckerman, K. F., Sgouros, G., Thomas, S. R., 2009. MIRD pamphlet No. 21: a generalized schema for radiopharmaceutical dosimetry--standardization of nomenclature. J Nucl Med 50, 477-484.

5. ISO, 2011. Radiation protection - Dose assessment for the monitoring of workers for internal radiation exposure. ISO 27048:2011. ISO, Geneva.

6. Castellani, C. M., Marsh, J. W., Hurtgen, C., Blanchardon, E., Berard, P., Giussani, A., Lopez, M. A., 2013. IDEAS Guidelines (Version 2) for the Estimation of Committed Doses from Incorporation Monitoring Data. EURADOS, Braunschweig, EURADOS Report 2013-01, http://www.eurados.org/ /media/Files/Eurados/documents/EURADOS\%20Report\%20201301\%20online\%20version.pdf?la=en.

7. Etherington, G., Berard, P., Blanchardon, E., Breustedt, B., Castellani, C. M., Challetonde Vathaire, C., Giussani, A., Franck, D., Lopez, M. A., Marsh, J. W., Nosske, D., 2016. Technical recommendations for monitoring individuals for occupational intakes of radionuclides. Radiat Prot Dosimetry 170, 8-12.

8. SFMT, 2011. Good practice recommendations. Medical Monitoring of occupational internal exposure to radionuclides in nuclear installations., http://www.chu$\underline{\text { rouen.fr/sfmt/autres/Internal_exposure_nuclear_instal_medical_monitoring_nov_2012.pdf }}$ - [Last accessed July 18, 2017].

9. Bertelli, L., Melo, D. R., Lipsztein, J., Cruz-Suarez, R., 2008. AIDE: internal dosimetry software. Radiat Prot Dosimetry 130, 358-367. 
10. Doerfel, H., 2007. IDEA system--a new computer-based expert system for incorporation monitoring. Radiat Prot Dosimetry 127, 425-429.

11. Birchall, A., Puncher, M., Marsh, J. W., 2007. Avoiding biased estimates of dose when nothing is known about the time of intake. Radiat Prot Dosimetry 127, 343-346.

12. Berkovski, V., Ratia, G., Bonchuk, Y., 2007. IMIE computer codes: 10 y in the internal dosimetry. Radiat Prot Dosimetry 125, 205-208.

13. Ishigure, N., Matsumoto, M., Nakano, T., Enomoto, H., 2004. Development of software for internal dose calculation from bioassay measurements. Radiat Prot Dosimetry 109, 235242.

14. Davesne, E., Vincent, M., Blanchardon, E., Rennesson, M., Laroche, P., Franck, D., 2014. OPSCI: Software to optimize individual routine monitoring programme of internal contamination, in: International Atomic Energy Agency (Ed.), International Conference on Occupational Radiation Protection: Enhancing the Protection of Workers - Gaps, Challenges and Developments, Vienna, Austria.

15. EUROPEAN COMMISSION, FOOD AND AGRICULTURE ORGANIZATION OF THE UNITED NATIONS, INTERNATIONAL ATOMIC ENERGY AGENCY, INTERNATIONAL LABOUR ORGANIZATION, OECD NUCLEAR ENERGY AGENCY, PAN AMERICAN HEALTH ORGANIZATION, UNITED NATIONS ENVIRONMENT PROGRAMME, WORLD HEALTH ORGANIZATION, 2014. Radiation Protection and Safety of Radiation Sources: International Basic Safety Standards. INTERNATIONAL ATOMIC ENERGY AGENCY, Vienna, $\underline{\text { http://www- }}$ pub.iaea.org/books/IAEABooks/8930/Radiation-Protection-and-Safety-of-RadiationSources-International-Basic-Safety-Standards.

16. IAEA, 2006. Manual for First Responders to a Radiological Emergency. INTERNATIONAL ATOMIC ENERGY AGENCY, Vienna, $\underline{\text { http://www- }}$ pub.iaea.org/books/IAEABooks/7606/Manual-for-First-Responders-to-a-Radiological-

\section{Emergency.}


17. European Council Directive 2013/59/Euratom on basic safety standards for protection against the dangers arising from exposure to ionising radiation and repealing Directives 89/618/Euratom, 90/641/Euratom, 96/29/Euratom, 97/43/Euratom and 2003/122/Euratom. 2014. Official Journal of the European Union, L13, 57, 1-73 http://data.europa.eu/eli/dir/2013/59/oj.

18. ICRP, 2009. Emergency exposure situation. ICRP Publication 109. Annals of the ICRP 39. 19. Lopez, M.A., Fojtik, P., Franck, D., Osko, J., Gerstmann, U., Scholl, C., Lebacq, A. L., Breustedt, B., del Risco Norrlid, L., 2016. Lessons learned from the EURADOS survey on individual monitoring data and internal dose assessments of foreigners exposed in Japan following the Fukushima Daiichi NPP accident. Radiat Prot Dosimetry 170, 402-406.

20. Li, C. , Ansari, A. , Bartizel, C. , Battisti, P. , Franck, D. , Gerstmann, U. , Giardina, I., Guichet, C. , Hammond, D. , Hartmann, M., Jones, R.L. , Kim, E. , Ko, R., Morhard, R. , Quayle, D. , Sadi, B., Saunders, D. , Paquet, F., 2016. GHSI emergency radionuclide bioassay laboratory network: Summary of recent exercice Radiat Prot Dosimetry 171, 351 357.

21. Li, C., Bartizel, C., Battisti, P., Böttger, A., Bouvier, C., Capote-Cuellar, A., Carr, Z., Hammond, D. , Hartmann, M., Heikkinen, T., Jones, R.L., Kim, E., Ko, R. , Koga, R. , Kukhta, B. A., Mitchell, L. , Morhard, R., Paquet, F., Quayle, D. , Rulik, P., Sadi, B. , Sergei, A., Sierra, I., de Oliveira Sousa, W., Szab, G., 2017. GHSI emergency radionuclide bioassay laboratory network - Summary of the second exercise Radiat Prot Dosimetry 174, 449-456.

22. Li, C., Battisti, P., Berard, P., Cazoulat, A. , Cuellar, A., Cruz-Suarez, R., Dai, X., Giardina, I., Hammond, D., Hernandez, C., Kiser, S., Ko, R., Kramer-Tremblay, S., Lecompte, Y., Navarro, E., Navas, C., Sadi, B., Sierra, I., Verrezen, F., Lopez, M.A., 2014. EURADOS intercomparison on emergency radiobioassay. Radiat Prot Dos 167, 472-484. 
23. Kim, E., Kurihara, O., Kunishima, N., Momose, T., Ishikawa, T., Akashi, M., 2016. Internal thyroid doses to Fukushima residents-estimation and issues remaining. J Radiat Res 57 Suppl 1, i118-i126.

24. INTERNATIONAL ATOMIC ENERGY AGENCY, 2005. Generic Procedures for Medical Response During a Nuclear or Radiological Emergency. INTERNATIONAL ATOMIC ENERGY AGENCY, Vienna, http://www-pub.iaea.org/books/IAEABooks/7213/Generic-Procedures$\underline{\text { for-Medical-Response-During-a-Nuclear-or-Radiological-Emergency. }}$

25. Rojas-Palma, C., Liland, A., Jerstad, A. N., Etherington, G., del Rosario Pérez, M., Rahola, T., Smith, K. , 2009. TMT Handbook. Triage, Monitoring and Treatment of People exposed to lonising Radiation following a Malevolent Act. . NRPA, Osteras, Norway, http://www.tmthandbook.org.

26. Etherington, G., Marsh, J., Gregoratto, D., Youngman, M., Franck, D., Lebacq, A. L., Isaksson, M., Osko, J., Gómez-Ros, J. M., Lopez, M. A., Fotjík, P., Malátová, I., Zagyvai, P., Gil, M., Teles, P., Vaz, P., Saizu, M., Vrba, T., Berkovskyy, V., Broggio, D., 2017. CAThyMARA report: Technical guidelines for radioiodine in thyroid monitoring. OPERRA Deliverable D5.31, https://www.researchgate.net/publication/321869578_CAThyMARA_report_Technical_guid elines_for_radioiodine_in_thyroid_monitoring_OPERRA_Deliverable_D531.

27. Vrba, T., Berkovskyy, V., Pospisil, V., Bonchuck, I., Likhtariov, I., Ratia, G., Lopez, M.A., Teles, P., Etherington, G., Zagyvai, P., Broggio, D., 2017. CAThyMARA report: Demonstration software, if relevant, for dose calculations in case of nuclear crisis, OPERRA Deliverable D5.29, https://www.researchgate.net/project/CAThyMARA-Child-and-AdultThyroid-Monitoring-After-Reactor-Accident-OPERRA-Project-number-

\section{$\underline{604984 / \text { update/59d7cafe4cde265f5d77a6c3. }}$}

28. Oughton, D., Albani, V., Barquinero, F., Chumak, V., Clero, E., Crouail, P., Fattibene, P., Kesminiene, A., Laurier, D., Liutsko, L., Ohba, T., Ostroumova, E., Pirard, P., Rogel, A., Sarukhan, A., Schneider, T., Tanigawa, K., Tomkiv, E., Vale, L., Cardis, E. , 2017. 
Recommendations and procedures for preparedness and health surveillance of populations affected by a radiation accident, https: / / www.isglobal.org/documents/10179/5808947/SHAMISEN+Recommendations+and+p $\underline{\text { rocedures+for+preparedness+and+health+surveillance+of+populations+affected+by+a+radia }}$ tion+accident+EN/f3df29c3-1c00-4004-91fc-3b0750d5458e.

29. Marsh, J. W., Laurier, D., Tirmarche, M., 2017. Radon Dosimetry for Workers: Icrp's Approach. Radiat Prot Dosimetry, 1-9.

30. Laurier, D., Guseva Canu, I., Baatout, S., Bertho, J. M., Blanchardon, E., Bouffler, S., Cardis, E., Gomolka, M., Hall, J., Kesminiene, A., Kreuzer, M., Rage, E., 2012. DoReMi workshop on multidisciplinary approaches to evaluating cancer risks associated with lowdose internal contamination. Radioprotection 47, 119-148.

31. Rowland, R. E., Stehney, A. F., Lucas, H. F., 1983. Dose-response relationships for radium-induced bone sarcomas. Health Phys 44 Suppl 1, 15-31.

32. Spiers, F. W., Lucas, H. F., Rundo, J., Anast, G. A., 1983. Leukaemia incidence in the U.S. dial workers. Health Phys 44 Suppl 1, 65-72.

33. Boice, J. D., Jr., Cohen, S. S., Mumma, M. T., Ellis, E. D., Cragle, D. L., Eckerman, K. F., Wallace, P. W., Chadda, B., Sonderman, J. S., Wiggs, L. D., Richter, B. S., Leggett, R. W., 2014. Mortality among mound workers exposed to polonium-210 and other sources of radiation, 1944-1979. Radiation research 181, 208-228.

34. Rage, E., Caer-Lorho, S., Drubay, D., Ancelet, S., Laroche, P., Laurier, D., 2015. Mortality analyses in the updated French cohort of uranium miners (1946-2007). International archives of occupational and environmental health 88, 717-730.

35. Kreuzer, M., Sobotzki, C., Fenske, N., Marsh, J. W., Schnelzer, M., 2017. Leukaemia mortality and low-dose ionising radiation in the WISMUT uranium miner cohort (1946-2013). Occupational and environmental medicine 74, 252-258.

36. Kreuzer, M., Fenske, N., Schnelzer, M., Walsh, L., 2015. Lung cancer risk at low radon exposure rates in German uranium miners. British journal of cancer 113, 1367-1369. 
37. Boice, J. D., Jr., Cohen, S. S., Mumma, M. T., Chadda, B., Blot, W. J., 2008. A cohort study of uranium millers and miners of Grants, New Mexico, 1979-2005. J Radiol Prot 28, 303-325.

38. Bouet, S., Samson, E., Jovanovic, I., Laurier, D., Laurent, O., 2018. First mortality analysis in the French cohort of uranium millers (F-Millers), period 1968-2013. International archives of occupational and environmental health 91, 23-33.

39. Kreuzer, M., Dufey, F., Laurier, D., Nowak, D., Marsh, J. W., Schnelzer, M., Sogl, M., Walsh, L., 2015. Mortality from internal and external radiation exposure in a cohort of male German uranium millers, 1946-2008. International archives of occupational and environmental health $88,431-441$.

40. Sokolnikov, M., Preston, D., Gilbert, E., Schonfeld, S., Koshurnikova, N., 2015. Radiation effects on mortality from solid cancers other than lung, liver, and bone cancer in the Mayak worker cohort: 1948-2008. PloS one 10, e0117784.

41. Gilbert, E. S., Sokolnikov, M. E., Preston, D. L., Schonfeld, S. J., Schadilov, A. E., Vasilenko, E. K., Koshurnikova, N. A., 2013. Lung cancer risks from plutonium: an updated analysis of data from the Mayak worker cohort. Radiation research 179, 332-342.

42. Kuznetsova, I. S., Labutina, E. V., Hunter, N., 2016. Radiation Risks of Leukemia, Lymphoma and Multiple Myeloma Incidence in the Mayak Cohort: 1948-2004. PloS one 11, e0162710.

43. Yiin, J. H., Anderson, J. L., Daniels, R. D., Bertke, S. J., Fleming, D. A., Tollerud, D. J., Tseng, C. Y., Chen, P. H., Waters, K. M., 2017. Mortality in a combined cohort of uranium enrichment workers. American journal of industrial medicine 60, 96-108.

44. Zhivin, S., Guseva Canu, I., Samson, E., Laurent, O., Grellier, J., Collomb, P., Zablotska, L. B., Laurier, D., 2016. Mortality (1968-2008) in a French cohort of uranium enrichment workers potentially exposed to rapidly soluble uranium compounds. Occupational and environmental medicine 73, 167-174. 
45. Grellier, J., Atkinson, W., Berard, P., Bingham, D., Birchall, A., Blanchardon, E., Bull, R., Canu Guseva, I., Challeton-de Vathaire, C., Cockerill, R., Do, M. T., Engels, H., Figuerola, J., Foster, A., Holmstock, L., Hurtgen, C., Laurier, D., Puncher, M., Riddell, A. E., Samson, E., Thierry-Chef, I., Tirmarche, M., Vrijheid, M., Cardis, E., 2017. Risk of lung cancer mortality in nuclear workers from internal exposure to alpha particle-emitting radionuclides. Epidemiology.

46. Zhivin, S., Guseva Canu, I., Davesne, E., Blanchardon, E., Garsi, J. P., Samson, E., Niogret, C., Zablotska, L. B., Laurier, D., 2017. Circulatory disease in French nuclear fuel cycle workers chronically exposed to uranium: a nested case-control study. Occupational and environmental medicine Accepted.

47. Napier, B. A., 2017. THE MAYAK WORKER DOSIMETRY SYSTEM (MWDS-2013): AN INTRODUCTION TO THE DOCUMENTATION. Radiat Prot Dosimetry, 1-4.

48. Anderson, J. L., Apostoaei, A. I., Thomas, B. A., 2013. Estimation of internal exposure to uranium with uncertainty from urinalysis data using the InDEP computer code. Radiat Prot Dosimetry 153, 64-73.

49. Bingham, D., Berard, P., Birchall, A., Bull, R., Cardis, E., Challeton-de Vathaire, C., Grellier, J., Hurtgen, C., Puncher, M., Riddell, A., Thierry-Chef, I., 2017. Reconstruction of Internal Doses for the Alpha-Risk Case-Control Study of Lung Cancer and Leukaemia Among European Nuclear Workers. Radiat Prot Dosimetry 174, 485-494.

50. Vostrotin, V., Birchall, A., Zhdanov, A., Puncher, M., Efimov, A., Napier, B., Sokolova, A., Miller, S., Suslova, K., 2016. The Mayak Worker Dosimetry System (MWDS-2013): Internal Dosimetry Results. Radiat Prot Dosimetry.

51. Anderson, J. L., Apostoaei, A. I., Yiin, J. H., Fleming, D. A., Tseng, C. Y., Chen, P. H., 2016. Internal exposure to uranium in a pooled cohort of gaseous diffusion plant workers. Radiat Prot Dosimetry 168, 471-477.

52. Laurent, O., Gomolka, M., Haylock, R., Blanchardon, E., Giussani, A., Atkinson, W., Baatout, S., Bingham, D., Cardis, E., Hall, J., Tomasek, L., Ancelet, S., Badie, C., Bethel, 
G., Bertho, J. M., Bouet, S., Bull, R., Challeton-de Vathaire, C., Cockerill, R., Davesne, E., Ebrahimian, T., Engels, H., Gillies, M., Grellier, J., Grison, S., Gueguen, Y., Hornhardt, S., Ibanez, C., Kabacik, S., Kotik, L., Kreuzer, M., Lebacq, A. L., Marsh, J., Nosske, D., O'Hagan, J., Pernot, E., Puncher, M., Rage, E., Riddell, T., Roy, L., Samson, E., Souidi, M., Turner, M. C., Zhivin, S., Laurier, D., 2016. Concerted Uranium Research in Europe (CURE): toward a collaborative project integrating dosimetry, epidemiology and radiobiology to study the effects of occupational uranium exposure. J Radiol Prot 36, 319-345.

53. Birchall, A., Puncher, M., Harrison, J., Riddell, A., Bailey, M. R., Khokryakov, V., Romanov, S., 2010. Plutonium worker dosimetry. Radiation and environmental biophysics 49, 203-212.

54. Birchall, A., Vostrotin, V., Puncher, M., Efimov, A., Dorrian, D., Riddell, A., Sokolova, A., Suslova, K., Zhdanov, A., 2013. Delivrable 3.1.5: Internal dosimetry protocol for the proposed Mayak-Sellafield worker epidemiological study SOLO-WP3.1-EC report-PU-Oct 2013 https://solo-fp7.eu/images/SOLO-D315_WP31mp.pdf [Last Accessed July 19th 2017]. 55. Puncher, M., Birchall, A., Bull, R. K., 2013. A Bayesian analysis of uncertainties on lung doses resulting from occupational exposures to uranium. Radiat Prot Dosimetry 156, 131 140.

56. Puncher, M., Riddell, A. E., 2016. A Bayesian analysis of plutonium exposures in Sellafield workers. J Radiol Prot 36, 1-19.

57. Riddell, A. E., Battersby, W. P., Peace, M. S., Strong, R., 2000. The assessment of organ doses from plutonium for an epidemiological study of the Sellafield workforce. Journal of Radiological Protection 20, 275.

58. Riddell, A. E., Birchall, A., Puncher, M., Efimov, A., Vostrotin, V., 2015. Delivrable 3.3.1: Report on the development and validation of plutonium dose assessment systems for epidemiological research. https://solo-fp7.eu/images/SOLO_-_Deliverable_3-31_Final_Report_on_plutonium_dose_assessment_systems.pdf [Last Accessed September 19th 2017]. 
59. Samson, E., Piot, I., Zhivin, S., Richardson, D. B., Laroche, P., Serond, A. P., Laurier, D., Laurent, O., 2016. Cancer and non-cancer mortality among French uranium cycle workers: the TRACY cohort. BMJ open 6, e010316.

60. Guseva Canu, I., Laurier, D., Caer-Lorho, S., Samson, E., Timarche, M., Auriol, B., Berard, P., Collomb, P., Quesne, B., Blanchardon, E., 2010. Characterisation of protracted low-level exposure to uranium in the workplace: A comparison of two approaches. Int J Hyg Environ Health 213, 270-277.

61. Liu, H., Wakeford, R., Riddell, A., O'Hagan, J., MacGregor, D., Agius, R., Wilson, C., Peace, M., de Vocht, F., 2016. A review of job-exposure matrix methodology for application to workers exposed to radiation from internally deposited plutonium or other radioactive materials. J Radiol Prot 36, R1-R22.

62. IRSN, 2016. La radioprotection des travailleurs - Exposition professionnelle aux rayonnements ionisants en France 2015. http://www.irsn.fr/FR/expertise/rapports_expertise/Documents/radioprotection/IRSN_Ra pport-Exposition-travailleurs-2015.pdf [Last accessed July 18th 2017].

63. Blanchardon, E, Bingham, D., Bull, R., Challeton-de Vathaire, C., Cockerill, R., Davesne, E., Giussani, A., A.-L., Le Bacq, Noßke, D., Marsh, J., Riddell, A., Tomášek, L., 2014. Dosimetric protocol (CURE internal deliverable D2.2) DoReMi-Low Dose Research Towards Multidisciplinary Integration-task 5.8 'CURE project'. 